\title{
Suspected immune mediated response to COVID-19 vaccine: two individual case reports
}

\author{
Sagar R. Bhimani ${ }^{1}$, Sapna D. Gupta ${ }^{2 *}$, Kamlesh P. Patel ${ }^{1}$, Supriya D. Malhotra ${ }^{1}$
}

\author{
${ }^{1}$ Department of Pharmacology, ${ }^{2}$ Department of Emergency Smt. NHL Municipal Medical College, Ahmedabad, \\ Gujarat, India
}

Received: 12 May 2021

Accepted: 03 June 2021

*Correspondence:

Dr. Sapna D. Gupta,

Email: sapna_gupta76@yahoo.com

Copyright: (C) the author(s), publisher and licensee Medip Academy. This is an open-access article distributed under the terms of the Creative Commons Attribution Non-Commercial License, which permits unrestricted non-commercial use, distribution, and reproduction in any medium, provided the original work is properly cited.

\begin{abstract}
SARS-CoV-2, the virus that causes coronavirus disease 19 (COVID-19), has spread rapidly around the world. Researchers have been working round the clock to develop effective vaccines, which people started receiving in December 2020. Therefore, careful follow-up and surveillance studies for continued vaccine safety monitoring will be needed to ascertain the potential risks of such adverse events or disease. Here, we present two individual cases of pancreatitis and typhilitis following COVID 19 vaccination. In the first case of a 38 years old male patient developed pancreatitis after 4 days of COVID 19 vaccination and in second case, of a 60 years old female patient developing typhilitis after just one day after vaccination. All possible causes of this occurrence were ruled out. Two main factors suggest a possible link to the vaccine, the chronology of the events and the incongruent immune response to the vaccine component. It is not possible to establish a direct causal relation between vaccination and adverse event following immunization; however, this report can be used to alert practitioners to this possibility of adverse event following immunization after COVID-19 vaccine.
\end{abstract}

Keywords: COVID 19 vaccine, Adverse event, Pancreatitis, Typhilitis, AEFI

\section{INTRODUCTION}

In March 2020, the world health organization (WHO) declared coronavirus disease 2019 (COVID-19) Pandemic, which is caused by severe acute respiratory syndrome coronavirus 2 (SARS-CoV-2). ${ }^{1}$ There was sudden surge of development of vaccine in to this public health emergency. All though usually vaccine long time to development. It is imperative that full range of side effect will not have been known due to limited clinical trial data available.

The current COVID-19 pandemic has urged the scientific community internationally to find answers in terms of therapeutics and vaccines to control SARS-CoV-2. ${ }^{2} \mathrm{We}$ need observations of enhanced disease in people receiving candidate COVID-19 vaccines to understand the risk of immune enhancement of disease. ${ }^{2}$ Neither principles of immunity nor preclinical studies provide a basis for prioritizing among the COVID-19 vaccine candidates with respect to safety at this time.

Rigorous clinical trial design and post licensure surveillance should provide a reliable strategy to identify adverse events, including the potential for enhanced severity of COVID-19 disease, after vaccination. ${ }^{2}$ Our suspicion regarding this AEFI become strong because there was temporal association between administration of vaccine and appearance of this Adverse event in apparently healthy individuals.

An autoimmune trigger may be the cause of some cases of pancreatitis and typhilitis, however, accurately diagnosing autoimmune related diseases can be 
challenging because of its variable characteristics and clinical presentations. , $^{3,4}$

The causes of acute pancreatitis and typhilitis are well documented ${ }^{5}$. Vaccine-induced pancreatitis and typhilitis may be a subset of this immunologically driven phenomenon. ${ }^{5}$ Necrotizing pancreatitis accounts for $5 \%$ of all cases of acute pancreatitis and is far more severe than the more common interstitial pancreatitis. ${ }^{5}$ COVID19 vaccine induced pancreatitis and typhilitis are rare possibilities. Here we report two individual cases of suspected adverse event following Immunization that occurred after COVID-19 vaccination.

\section{CASE REPORT}

\section{Case 1}

A 38 years old male patient was brought to emergency medicine department of a tertiary hospital with complain of generalized abdominal pain in the last 4-5 days and 810 episodes of vomiting 3-4 days ago which was non projectile, non-bilious and containing food particles. No history of fever, diarrhoea, burning micturition or alcohol intake. No history of DM, HTN, TB or any surgical history. Patient took COVID-19 vaccine (Covishield) 11 days before admission. On admission the patient was conscious and oriented, with elevated S. Amylase (820 U/L), S. Lipase (982 U/L). Temperature was 98.4 F, BP130/80 mmHg, RR-18/min, pulse-134/min and SPO2$90 \%$ on room air which was maintaining on $97 \%$ SPO2 on $4 \mathrm{~L}$ nasal prong. His investigations on the day of admission were as follows: $\mathrm{Hb}: 11 \mathrm{~g} / \mathrm{dl}, \mathrm{WBC}: 16045$ cells/cumm, platelets: 3,00,007 cells/cumm, creatinine: $0.56 \mathrm{mg} / \mathrm{dL}$, urea:33.4 mg/dl, SGPT: 16U/L, SGOT: 23U/L, ALP: 46U/L, albumin:3.6g/dl, S. amylase 727 U/L, S. lipase $485 \mathrm{U} / \mathrm{L}$ and inflammatory markers like Ddimer:4.55 $\mu \mathrm{g} / \mathrm{ml}(<0.5)$ and CRP:313.61mg/L $(<5.0)$. The patient tested negative for COVID-19 by rapid antigen testing and RTPCR. Patient SARS-Cov-2 antibody titter was 1.15 (reactive).

Table 1: S. amylase and S. lipase report value prior and during hospitalization.

\begin{tabular}{|l|l|l|}
\hline Parameters & S. amylase U/1 & S. lipase U/1 \\
\hline $\begin{array}{l}\text { Prior to } \\
\text { admission }\end{array}$ & 820 & 982 \\
\hline After 2 days & 127 & 57 \\
\hline
\end{tabular}

Radiological investigation high resolution computed tomography of thorax report shows bilateral mild pleural effusion and cardiomegaly with changes of pulmonary arterial hypertension. USG abdomen shows pancreas obscured and mild ascites was noted. Multi-detector tomography scan of abdomen with pelvis shows acute necrotizing pancreatitis (modified CTSI score 8/10) (Figure 2) and $\mathrm{B} / \mathrm{L}$ mild pleural effusion. He was given injection meropenem $1 \mathrm{gm} \mathrm{IV}$ thrice a day, injection pantoprazole $40 \mathrm{mg}$ IV once a day, injection ondansetron $4 \mathrm{mg}$ IV thrice a day, injection ulinastatin 1 LACU IV once a day on the day of admission. On day 2, injection L-alanyl-L-glutamine $100 \mathrm{mg}$ IV once a day was given. On day 3 serum amylase and serum lipase was returning to base line (S. amylase $127 \mathrm{U} / 1$ and $\mathrm{S}$. lipase $57 \mathrm{U} / \mathrm{l}$ ).

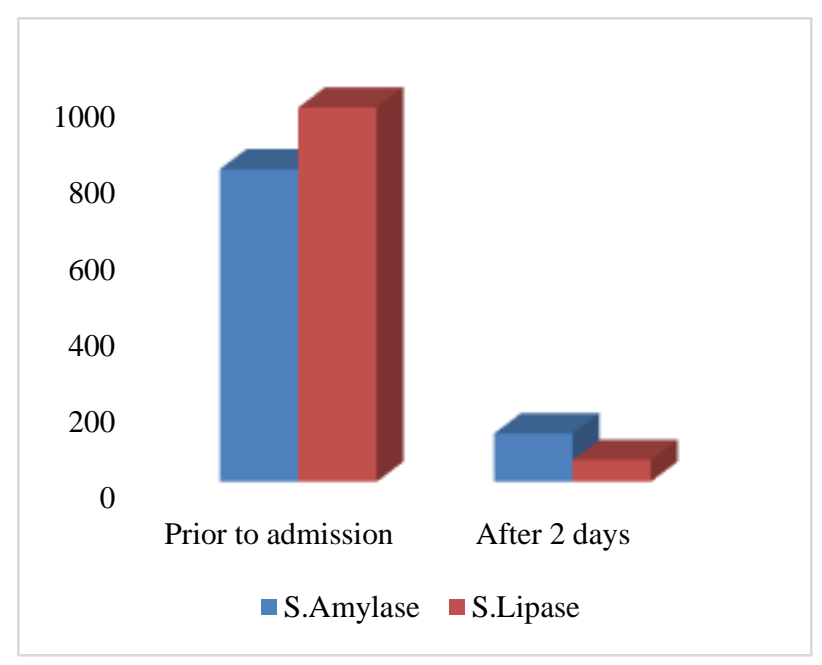

Figure 1: S. amylase and S. lipase report value prior and during hospitalization.

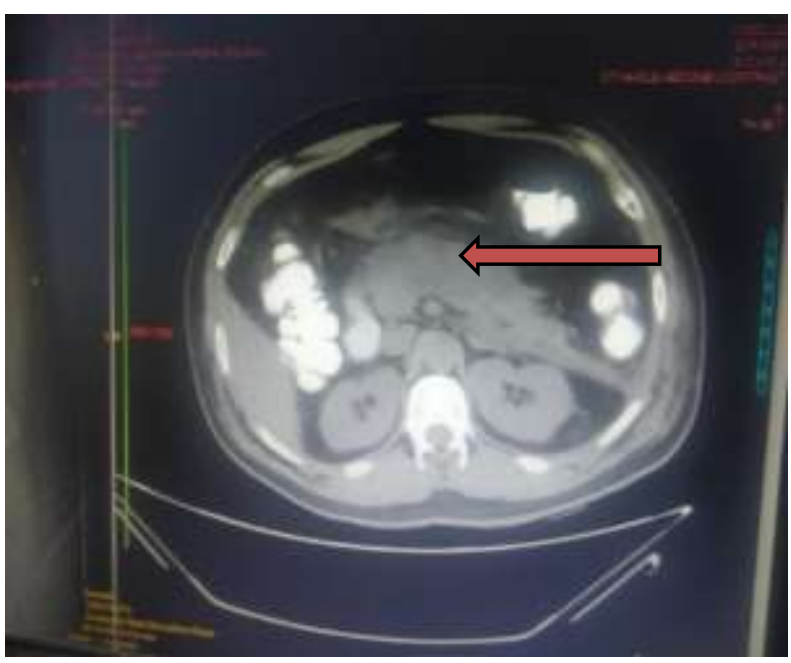

Figure 2: Patient's contrast-enhanced CT scan at the level of splenic vein, which shows pancreatic parenchyma appears bulky. Few non-enhancing necrotic areas noted in uncinate process, head and body of pancreas. Findings are consistent with acute necrotizing pancreatitis (modified CTSI score 8/10).

Patient did not have any significant past history and any concomitant medications were not used. Clinical and Radiological findings suggested that pancreatitis occurred after taking vaccine. Also, we rule out all possible causes of pancreatitis. Hence it is not possible to establish a direct causal relation between vaccination and pancreatitis. However, this report can be used to alert practitioners to the rare possibility of necrotizing pancreatitis after COVID-19 vaccine. 


\section{Case 2}

A 60 years old female patient was brought to emergency medicine department of tertiary hospital with complain of fever not associated with chills and rigors in the last 8 days, abdominal pain located to right side radiating to back side in the last 8 days and 01 episode of vomiting in the last 1 day which was non projectile, non-bilious and containing food particles. No diarrhoea, burning micturition or no history of alcohol intake. Patient did not have any comorbid conditions. Patient was relatively asymptomatic before 8 days on admission and then patient developed fever after COVID-19 vaccine (Covishield) which was took 8 days before admission.

On admission the patient was conscious and oriented. Temperature was $98.0 \mathrm{~F}$, BP-108/68 mmHg, RR-26/min, pulse-70/min and SPO2-90\% on O2 mask 6 1/min which was maintaining on $99 \%$ SPO2 on NRBM 14 1/min. Patient SARS-Cov-2 antibody titter was 0.07 (nonreactive)

Radiological investigation high resolution computed tomography of abdomen and pelvis done which was suggested of "large lesion on left lobe of liver without significant vascularity within and with peri hepatic free fluid-likely abscess. Appendix is inflamed $9 \mathrm{MM}$ possibility of typhilits with developing liver abscess (likely amoebis)". USG abdomen was done which was suggested of "oedematous and thickened wall of terminal ileum, ileo caecal junction and base of caecum noted, with maximum wall thickness of base of caecum measuring approximately $4.5 \mathrm{~mm}$. Approximately $8 \mathrm{~mm}$ sized secondarily inflamed appendix is noted in right iliac fossa. Mild free fluid is noted in inter bowel region”.

\begin{tabular}{|llll|}
\hline $\begin{array}{l}\text { Invest- } \\
\text { igation }\end{array}$ & $\begin{array}{l}\text { Observed } \\
\text { values }\end{array}$ & $\begin{array}{l}\text { Invest- } \\
\text { igation }\end{array}$ & $\begin{array}{l}\text { Observed } \\
\text { values }\end{array}$ \\
\hline HB & $10 \mathrm{mg} / \mathrm{dl}$ & IL-6 & $22.4 \mathrm{Pg} / \mathrm{ml}$ \\
\hline WBC & $\begin{array}{l}14950 \\
\text { cells/cumm }\end{array}$ & D-Dimer & $6.92 \mu \mathrm{g} / \mathrm{ml}$ \\
\hline Platelets & $\begin{array}{l}3,21,000 \\
\text { cells/cumm }\end{array}$ & CRP & $352.27 \mathrm{mg} / 1$ \\
\hline Neutrophil & $89 \%$ & ESR & $120 \mathrm{~mm} / \mathrm{hr}$ \\
\hline Amylase & $29 \mathrm{U} / 1$ & Ammonia & $115.5 \mathrm{mcq} / \mathrm{dl}$ \\
\hline Lipase & $24 \mathrm{U} / 1$ & SGOT & $48 \mathrm{U} / 1$ \\
\hline Creatinine & $1.54 \mathrm{mg} / \mathrm{dl}$ & SGPT & $88 \mathrm{U} / 1$ \\
\hline
\end{tabular}

Table 2: Blood investigation during hospitalization.

On Admission she was treated with injection meropenem $1 \mathrm{gm} \mathrm{IV}$ twice a day, injection metronidazole $100 \mathrm{ml}$ IV thrice a day, injection pantoprazole $40 \mathrm{mg} I V$ once a day, injection ondansetron $4 \mathrm{mg}$ IV thrice a day, injection albumin 20\% IV for 5 days, injection heparin 5000 IU 6 hourly for 5 days, neb. duolin 6 hourly, tab. MVBC twice a day, tab. limcee $500 \mathrm{mg}$ thrice a day, tab. livogen once a day. Finally on $12^{\text {th }}$ day, patient was discharged with stable condition.

Patient did not have any significant past history and any concomitant medication was not used. Clinical and Radiological findings suggested that typhilitis occurred after taking vaccine. All possible causes of typhilitis were ruled out. It is not possible to establish a direct causal relation between vaccination and typhilitis.

\section{DISCUSSION}

We present 2 cases of acute necrotizing pancreatitis and Typhilitis in a person who had recently received COVID19 vaccine. Extensive patient history as well as laboratory and imaging investigations did not reveal any known precipitants of pancreatitis and typhilitis.

In this case, the temporal relation between the vaccination and the onset of necrotizing pancreatitis and typhilitis suggests that the events are associated. Although the exact mechanism linking vaccination and vaccine induce pancreatitis and typhilitis was unknown. For vaccine induced pancreatitis, some authors postulate that the activation of pancreatic zymogens by serum factors can initiate acinar cell injury. ${ }^{6}$ There are also suggestions in the literature of several additional mechanisms of immunologic injury such as polyclonal activation (adjuvant reaction) of lymphocytes, "by stander activation" of self-reactive lymphocytes or somatic mutation of immunoglobulin variable genes. ${ }^{7}$

In the present case, pancreatitis developed within 3 to 4 days following the first dose of the vaccine. This was clearly within the time period when adverse event following Immunization would be expected to occur. Typhlitis is acute inflammation of the caecum and ascending colon that is typically seen in immunocompromised or immunosuppressed patients (e.g., acquired immune deficiency syndrome or leukaemia, transplant recipients, or after chemotherapy. It is a critical condition that is associated with high mortality. Its pathogenesis is not fully understood.

The pathology of typhilits is not yet entirely clear and is likely secondary to multiple underlying causes. ${ }^{7}$ Typhilits also reportedly occurs in patients with neutropenia, myelodysplastic syndrome, solid malignancy, and patients with autoimmune conditions on immune suppressive medications. ${ }^{7}$ In our case no other causes have been found other than the vaccine. It was rare occurrence of thyphilits after taken vaccine, it might be due to immunologic injury may be caused by a cytotoxic antibody which was vaccine induced and it that disrupt the mucosal barrier, which allows bacterial translocation from the gut and developed typhilitis.

Since potential long-term adverse effects (mediated by immune or non-immune mechanisms) cannot be ruled out, careful follow-up and surveillance studies for 
continued vaccine safety monitoring will be needed to ascertain the potential risks of such adverse events or diseases. ${ }^{8}$

\section{CONCLUSION}

The benefits and risks of current COVID-19 vaccines must be weighed against the real possibility of contracting the disease and developing complications and long-term sequels. Here presented two reports implies a message that we also prepare the vigilance systems necessary to digitally track the physical administration of a future available vaccine and ensure that public safety surveillance monitoring will be in place to protect public health.

Funding: No funding sources Conflict of interest: None declared

Ethical approval: Not required

\section{REFERENCES}

1. WHO director-general's opening remarks at the media briefing on COVID-19. Abailable at: https://www.who.int/dg/speeches/detail/who-

director-general-s-opening-re. Accessed on 7 September 2020.

2. Haynes BF, Corey L, Fernandes P, Gilbert PB, Hotez PJ, Rao S, et al. Prospects for a safe COVID-19 vaccine. Sci Transl Med. 2020;12(568):445-9.
3. Sarles H, Sarles JC, Muratore R. Chronic inflammatory sclerosis of the pancreas-An autonomous pancreatic disease?. Am J Dig Dis. 1961;6:688-98.

4. Sahel J, Barthet M, Gasmi M. Autoimmune pancreatitis: increasing evidence for a clinical entity with various patterns. Eur J Gastroenterol Hepato.l 2004; $16: 1265-8$.

5. Shlomovitz E, Davies W, Cairns E, Brintnell WC, Goldszmidt M, Dresser GK. Severe necrotizing pancreatitis following combined hepatitis A and B vaccination. CMAJ. 2007;176(3):339-42.

6. Janigan DT, Nevalainen TJ, MacAulay MA. Foreign serum-induced pancreatitis in mice. I. A new model of acute pancreatitis. Lab Invest. 1975;33:591-607.

7. Urbach DR, Rotstein OD, Typhlitis. Canadian journal of surgery. J Canad de Chirurgie. 1999; 42(6):415-9.

8. Kostoff RN, Kanduc D, Porter AL, Shoenfeld Y, Calina D, Briggs MB, et al. Vaccine- and natural infection-induced mechanisms that could modulate vaccine safety. Toxicol. Rep. 2020;7:1448-58.

Cite this article as: Bhimani SR, Gupta SD, Patel KP, Malhotra SD. Suspected immune mediated response to COVID-19 vaccine: two individual case reports. Int J Basic Clin Pharmacol 2021;10:851-4. 